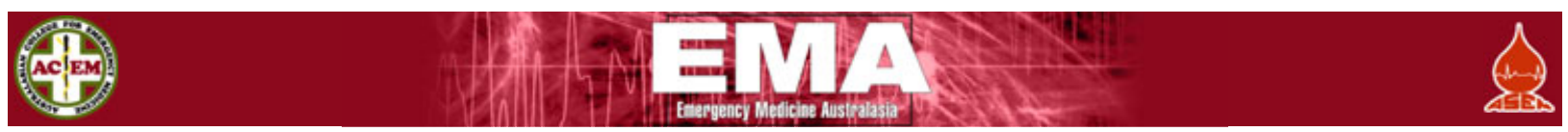

\title{
Access block and ED overcrowding
}

\author{
Roberto Forero, ${ }^{1}$ Kenneth M Hillman, ${ }^{1}$ Sally McCarthy, ${ }^{2}$ Daniel M Fatovich, ${ }^{3}$ Anthony P Joseph ${ }^{4}$ and \\ Drew B Richardson ${ }^{5}$ \\ ${ }^{1}$ Simpson Centre for Health Services Research Affiliated with The Australian Institute of Health \\ Innovation, University of New South Wales, Kensington, New South Wales, ${ }^{2}$ Department of Emergency \\ Medicine, Prince of Wales Hospital, Randwick, New South Wales, ${ }^{4}$ Royal North Shore Hospital and \\ University of Sydney, Sydney, New South Wales, ${ }^{3}$ Department of Emergency Medicine, Royal Perth \\ Hospital and University of Western Australia, Perth, Western Australia, ${ }^{5}$ Australian National University \\ Medical School, Canberra, ACT, Australia
}

\section{Abstract}

Key words: $\quad$ access block, emergency department, overcrowding.

Prospective and retrospective access block hospital intervention studies from 1998 to 2008 were reviewed to assess the evidence for interventions around access block and ED overcrowding, including over 220 documents reported in Medline and data extracted from The State of our Public Hospitals Reports. There is an estimated 20-30\% increased mortality rate due to access block and ED overcrowding. The main causes are major increases in hospital admissions and ED presentations, with almost no increase in the capacity of hospitals to meet this demand. The rate of available beds in Australia reduced from 2.6 beds per 1000 (1998-1999) to 2.4 beds per 1000 (2002-2007) in 2002, and has remained steady at between $2.5-2.6$ beds per 1000. In the same period, the number of ED visits increased over $77 \%$ from 3.8 million to 6.74 million. Similarly, the number of public hospital admissions increased at an average rate of $3.4 \%$ per year from 3.7 to 4.7 million. Compared with 1998-1999 rates, the number of available beds in 2006-2007 is thus similar (2.65 vs 2.6 beds per 1000), but the number of ED presentations has almost doubled. All patient groups are affected by access block. Access block interventions may temporarily reduce some of the symptoms of access block, but many measures are not sustainable. The root cause of the problem will remain unless hospital capacity is addressed in an integrated approach at both national and state levels.

\section{Introduction}

In the last decade, access block and ED overcrowding have been defined, investigated and managed through different initiatives across the Australian States, Territories and internationally. However, the problem of access block is far from being resolved with bed occupancy rates over $90 \%$ in most Australian public

Correspondence:

Dr Roberto Forero, Simpson Centre for Health Services Research, University of New South Wales, Locked Bag 7103, Liverpool Hospital, Liverpool BC, NSW 1871, Australia. Email: r.forero@unsw.edu.au

Roberto Forero, MA, MPH, PhD, Senior Research Fellow; Kenneth M Hillman, MB BS, FRCAnes, FFICANZCA, Professor, Director; Sally McCarthy, MB BS, FACEM, MBA, Director; Daniel M Fatovich, MB BS, FACEM, Professor; Drew B Richardson, MB BS(Hons), FACEM, Director, Associate Professor; Anthony P Joseph, MB BS, FACEM, MRCP, Senior Staff Specialist, Director, Clinical Senior Lecturer. 
hospitals, ${ }^{1}$ increases in ED presentations ${ }^{2}$ and despite major policy changes proposed and or implemented in the last few years across Australia.,

Access block is defined by the ACEM as 'the situation where patients are unable to gain access to appropriate hospital beds within a reasonable amount of time, no greater than 8 hours'. ED Overcrowding is defined as 'the situation where ED function is impeded by the number of patients waiting to be seen, undergoing assessment and treatment, or waiting for departure, exceeding the physical or staffing capacity of the department' 5

The purpose of this report is to update, summarize and integrate the evidence concerning access block and ED overcrowding by looking at trends in hospital admissions and bed availability, the contribution of access block and ED overcrowding to patient mortality and the quality of the studies conducted to date. Other literature reviews have also been conducted in recent years. ${ }^{2,6-9}$

This report provides an overview of access block studies, and explores hospital, patient or medical interventions to reduce its impact in terms of ambulance diversion, impaired access to emergency care, compromised clinical care, prolonged pain and suffering, comorbidity and mortality associated with prolonged ED length of stay.

\section{Methods}

Studies were appraised according to the following characteristics: type of intervention to reduce access block, quality of the study design, the level of evidence according to National Health and Medical Research Council (NHMRC) grades of recommendation, ${ }^{10}$ methods and outcomes. ${ }^{6-9}$

Peer reviewed literature was sourced from Medline for the published literature and Google for unpublished papers and websites. Table 1 describes the methods used for searching and selecting research papers, including the inclusion and exclusion criteria, keyword and MeSH terms strategy and online databases accessed.

\section{Results}

The search in Medline using the keyword 'Access Block' identified 47 articles and using the keyword 'Overcrowding' identified 1208 articles. A second search using keywords 'Access Block' or 'Crowding' or 'Overcrowding and ED' identified 533 articles. This demon- strates rapid growth in the published literature as an identical Medline search published in the Medical Journal of Australia in 2007 reported 163 articles. ${ }^{11}$ We compiled and reviewed 220 documents including policy reports, research papers, press releases, opinion documents (letters and editorials) and other relevant professional associations' website information.

\section{Decline in numbers of inpatient beds}

There has been a decline of $15-30 \%$ in the number of inpatient beds since the early 1990s across all major hospitals in Australia.,12-14 The last 5 years of available data from State of Our Public Hospitals ${ }^{15-17}$ show that the rate of available beds per 1000 population nationally has remained steady, whereas the average number of ED presentations and admissions per year has increased dramatically. Public hospital admissions increased from 3.7 million in 1998-1999 to 4.7 million in 2006-2007, an increase of $3.4 \%$ per year. The trend of ED presentations and bed availability are summarized in Figures 1 and $2 .^{15-17}$

The number of available beds in 2006-2007 is similar to 1998-1999, yet the number of ED presentations has almost doubled from 3.5 to 6.7 million (see Fig. 2). ${ }^{15-17}$ It is also important to note that the 2006, 2007 and 2008 reports present a different baseline 1998-1999 rate compared with the same data reported in the 2005 report ( 2.9 vs 2.65 beds per 1000). Some inconsistencies may be as a result of differences in the way weighted populations were calculated. ${ }^{15,17}$

\section{ED presentations}

The rate of ED presentations per 1000 population in Australia has increased from 202 in 2003-2004 to 208 in 2004-2005, 223 in 2005-2006 and to 311 in 2006-2007, according to the State of Our Public Hospitals Reports. This represents 1.98 million more presentations to Australian ED in 2006-2007 compared with the 2005-2006 financial year. ${ }^{15-17}$ Bed occupancy rates in most hospitals exceed $85 \%$ as a result of the increased demand and bed shortages, a level which is considered the maximum for efficient care and surge capacity.,2,6,714,18-24

\section{Increased patient mortality associated with access block and overcrowding}

Access block and overcrowding are associated with increased patient mortality. Different authors have estimated that there is a $20-30 \%$ excess mortality rate 


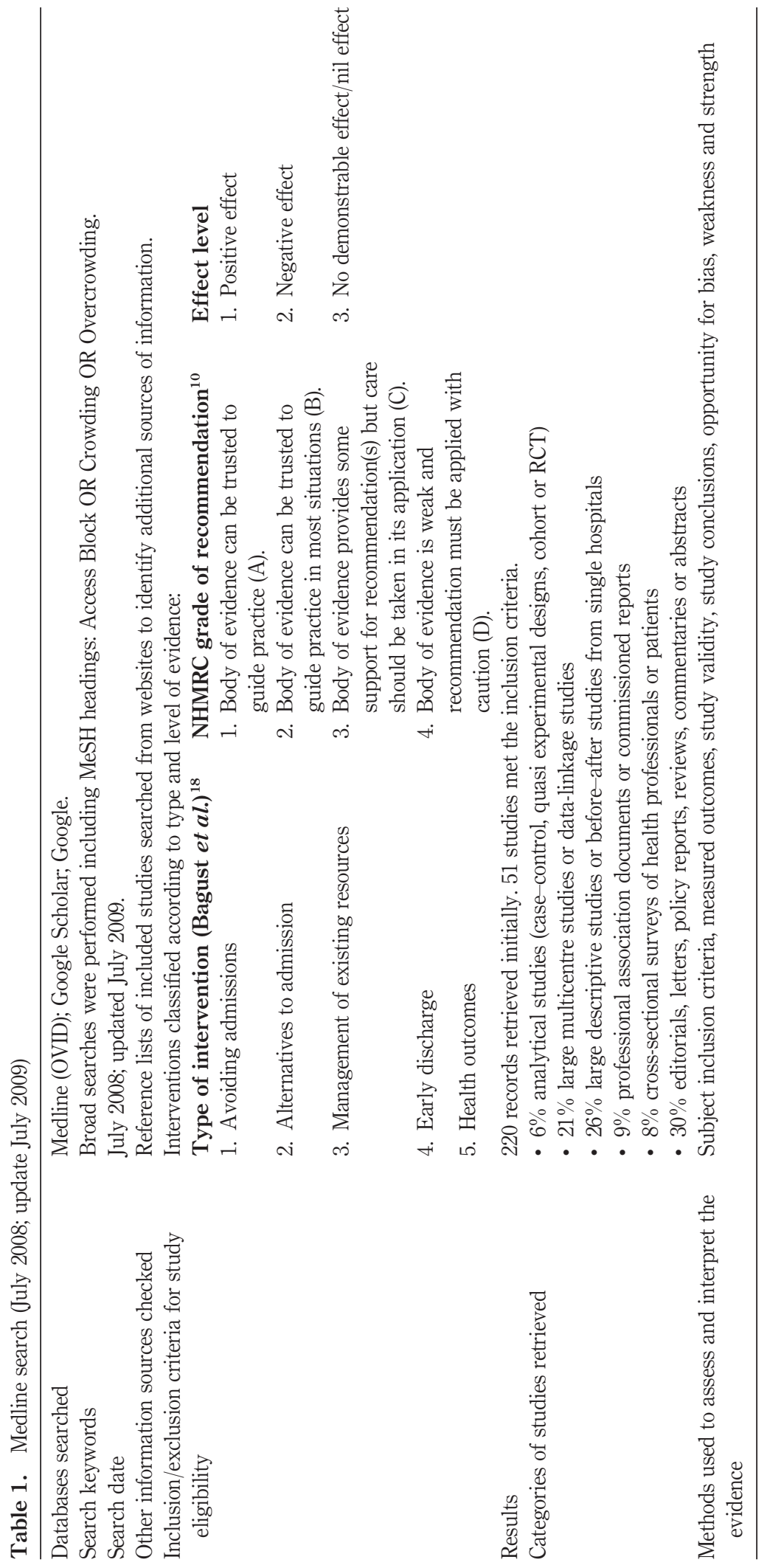




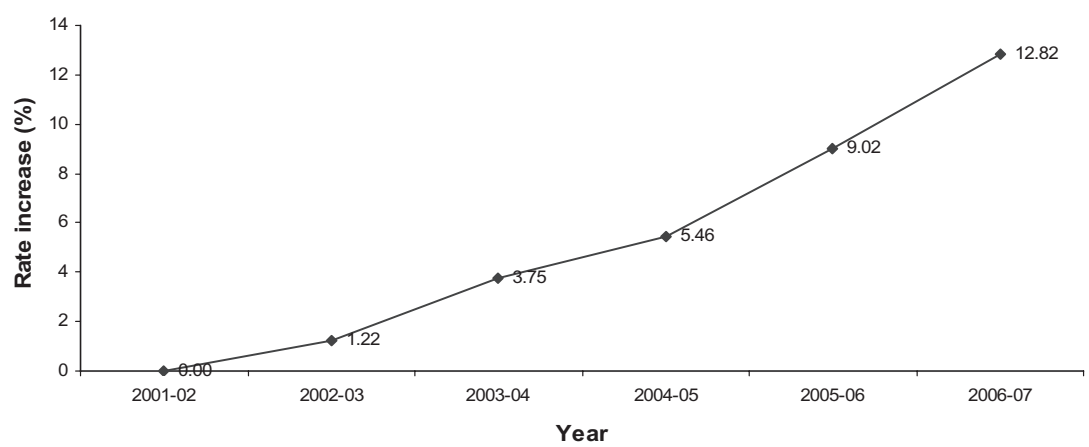

Figure 1. Relative increase of acute hospital overnight separations by $32.2 \%$ over the 5 years (2001-2007).

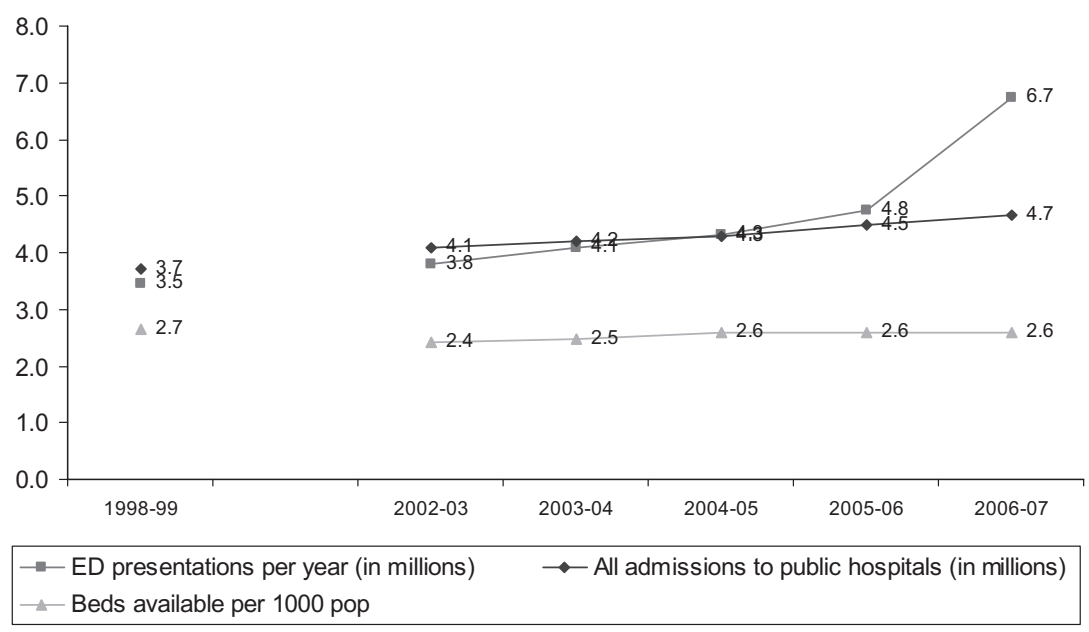

Figure 2. Trends in Australian ED utilization, hospital admissions and bed availability (2002-2007).

annually attributable to access block and ED overcrowding in Australia. ${ }^{25-27}$ This equates to approximately 1500 deaths per year, which is similar to the 2006-2007 Australian road toll. ${ }^{28}$

\section{Quality of interventions}

Bagust et al. ${ }^{18}$ have suggested that interventions to avoid or alleviate the effects of rising emergency admissions may be grouped into four categories: avoiding admissions, alternatives to admission, better management of existing resources and early discharge (see Table 2). Of the 220 papers examined in the present study, $70 \%$ provided data from NHMRC grades of recommendation levels of evidence A-CI-IV (See Table 1) and $30 \%$ were opinion documents from editorials, letters, policy reports, reviews, commentaries or abstracts (Type D). Results by journal showed Medical
Journal of Australia and Annals of Emergency Medicine had published 52 papers each; Emergency Medicine Journal and Emergency Medicine Australasia 12 papers each; and the Journal of Emergency Medicine had published 5 papers.

Multifaceted, multidisciplinary and hospital interventions are believed more likely to improve health outcomes than single-faceted and single hospital interventions. ${ }^{13,14}$ However, $89 \%$ of the evidence reported in Table 2 derives from single hospital interventions ${ }^{19-23,25-26,29-44,46,49-63,65,67-71}$ and only $11 \%$ from multicentre interventions. ${ }^{27,45,47-48,64}$

\section{Summary of the evidence on access block and ED overcrowding}

Table 2 provides a summary of publications of the evidence on access block and ED overcrowding 


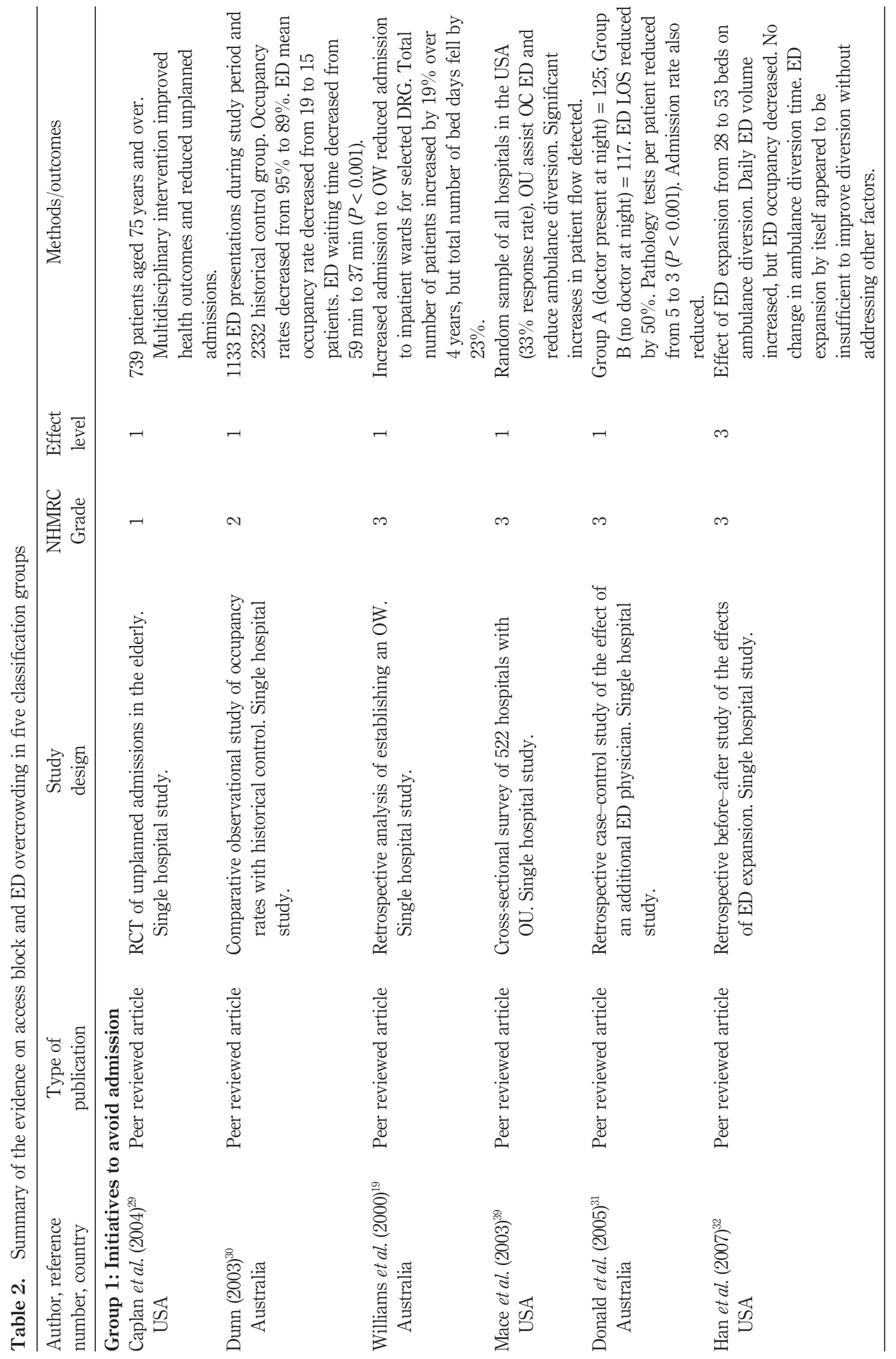




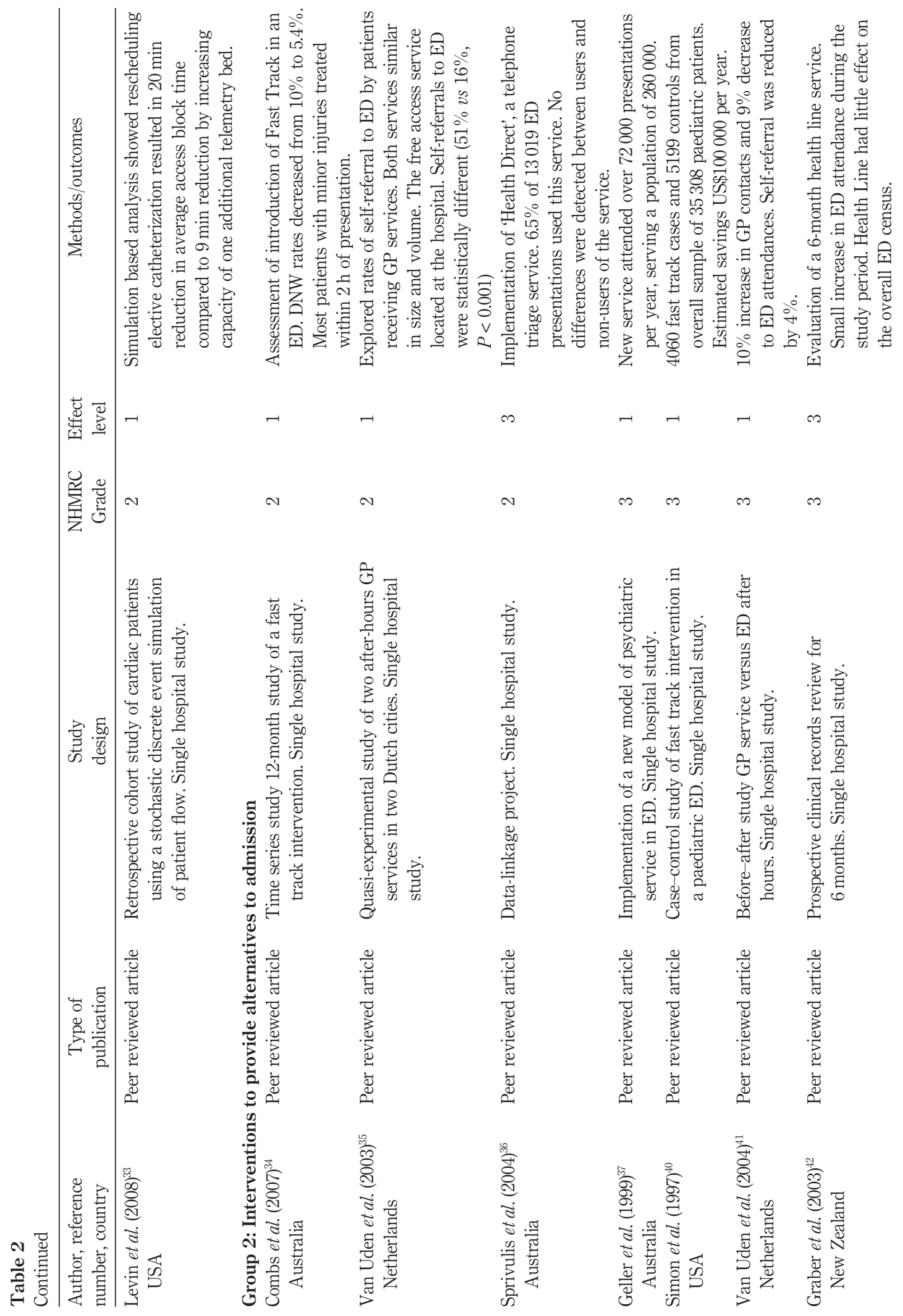




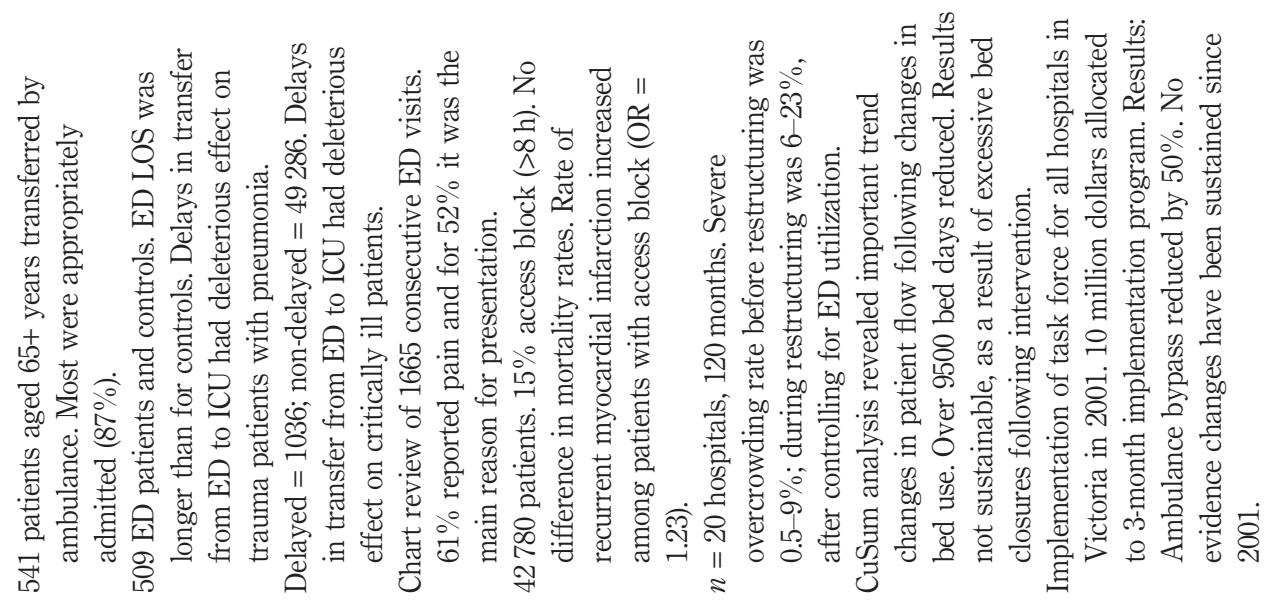

N

N

v

N

v

N

$m$

$m$

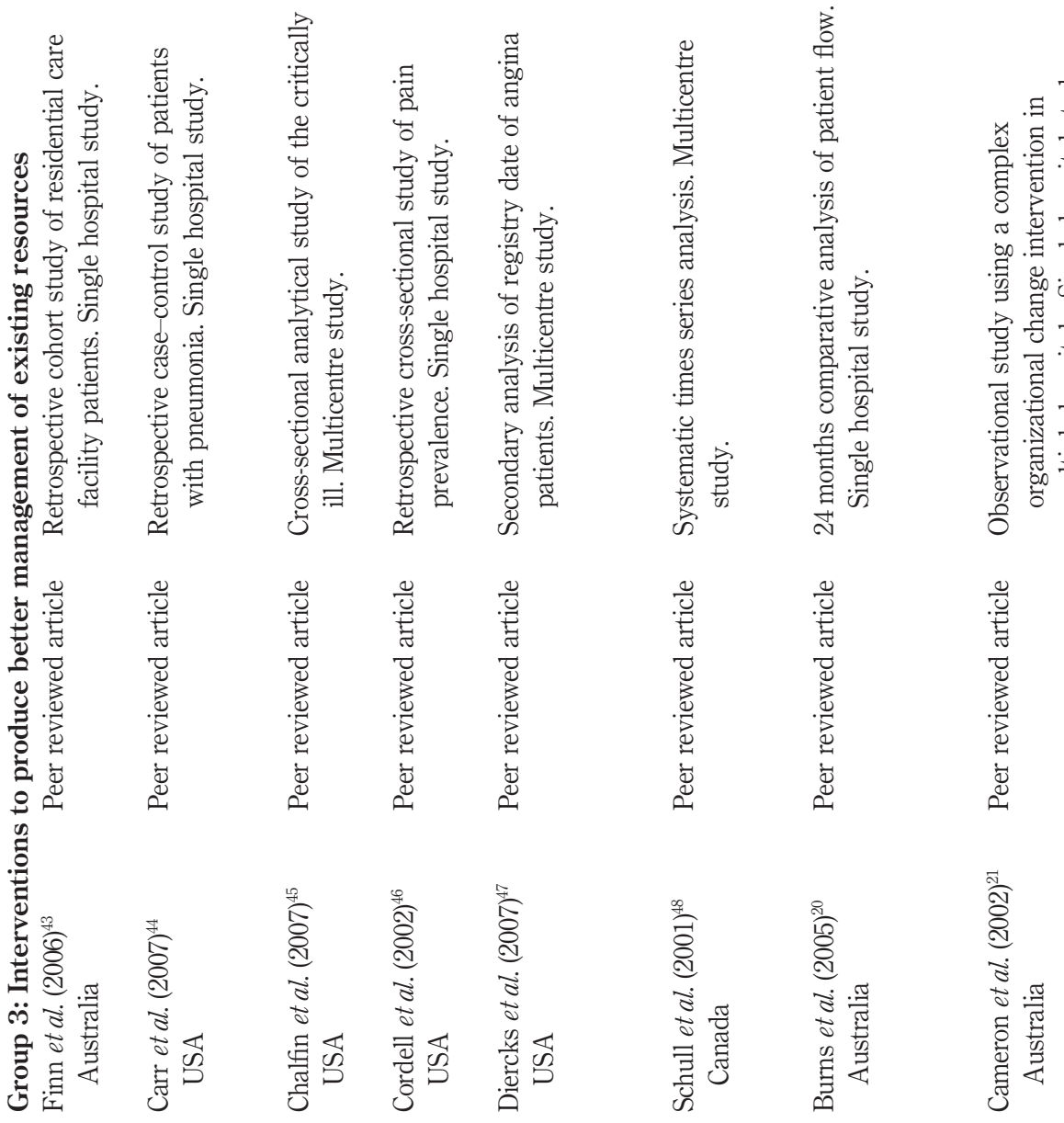




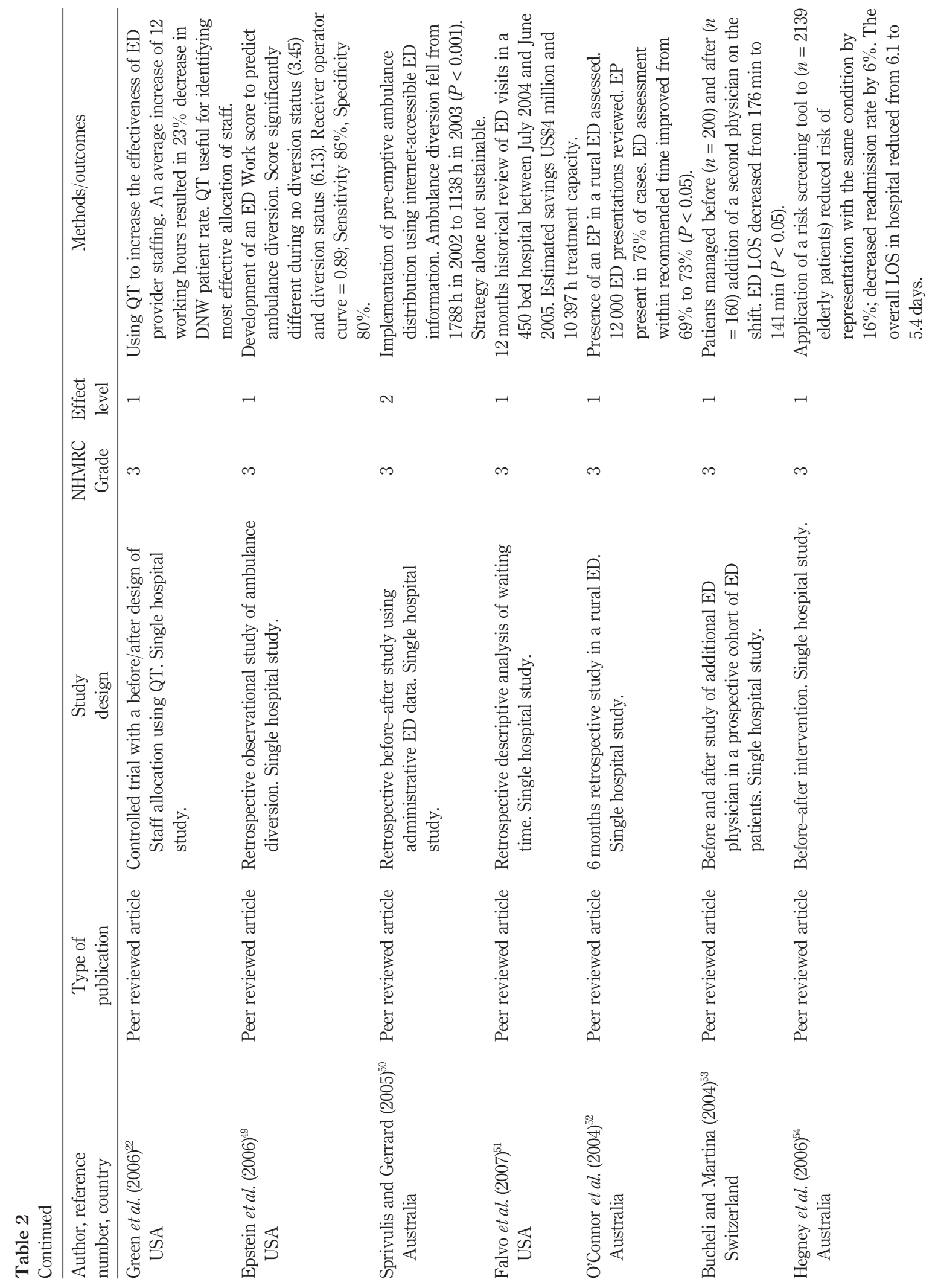



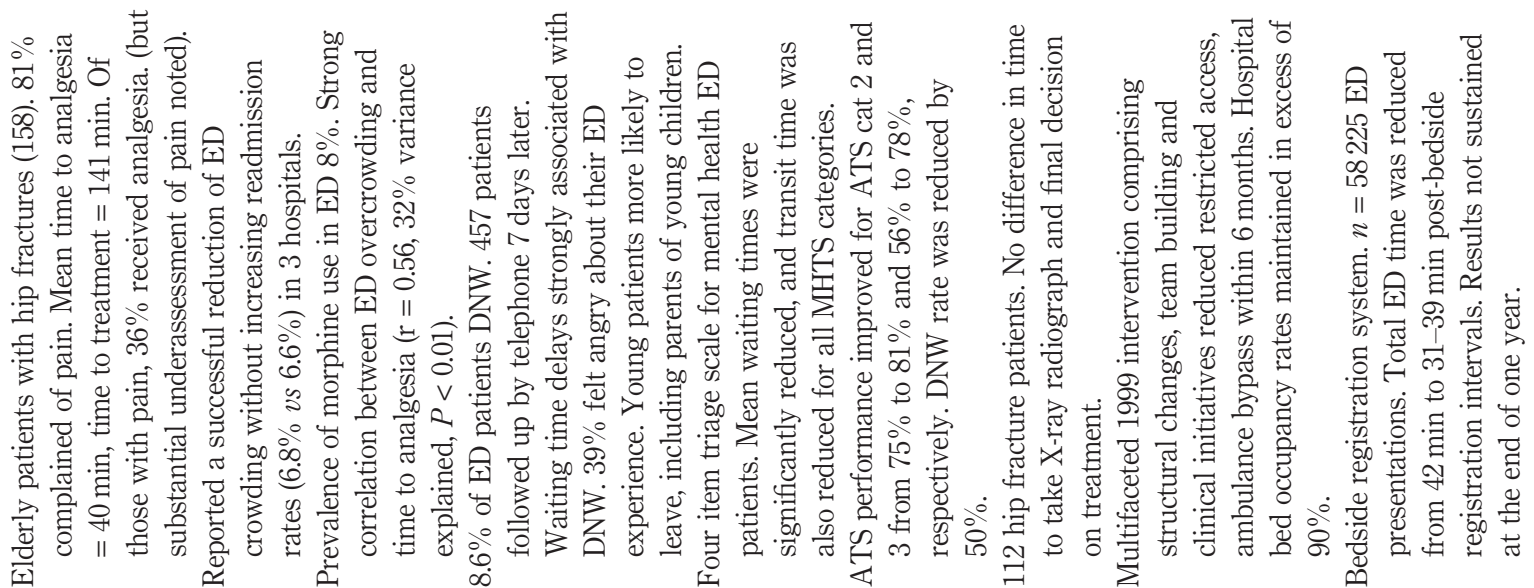

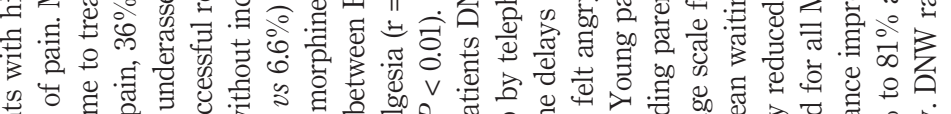

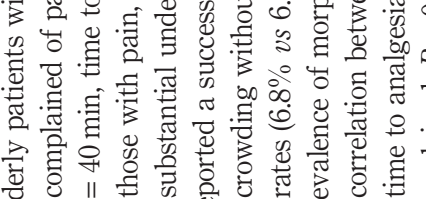

荧

$+$

$\sim$

$n$

๓

๓

๓
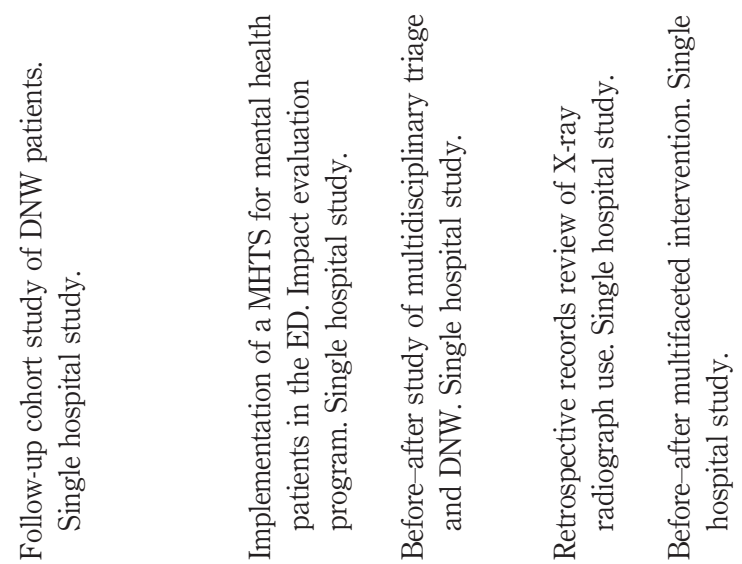

की

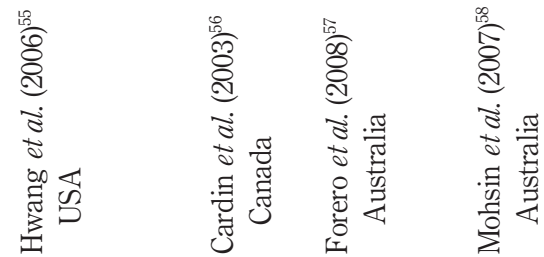

苞

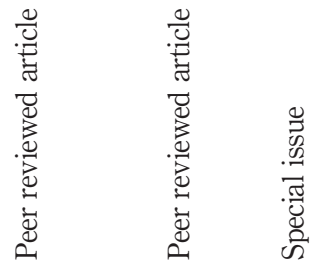

$\infty$
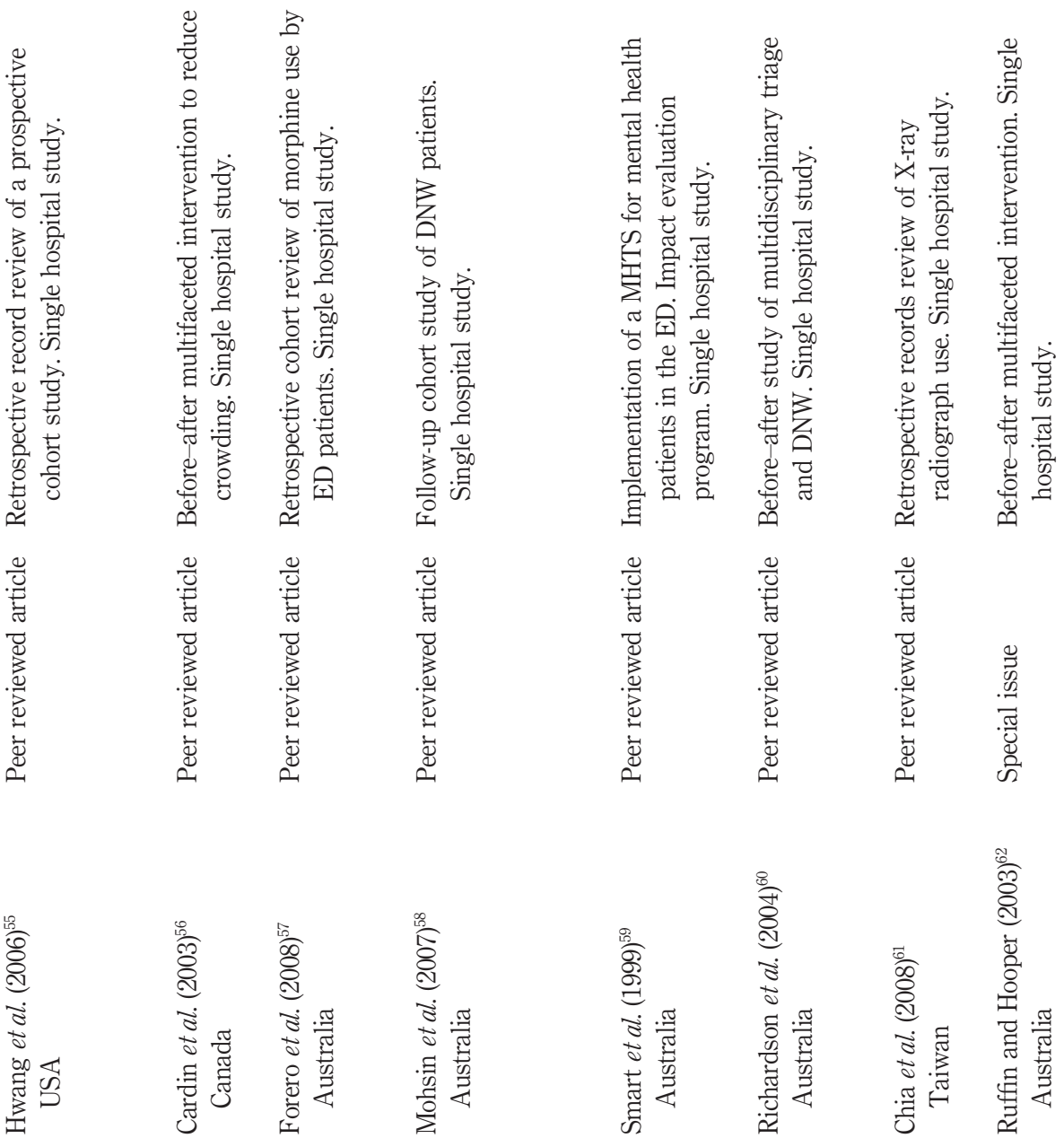

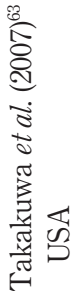




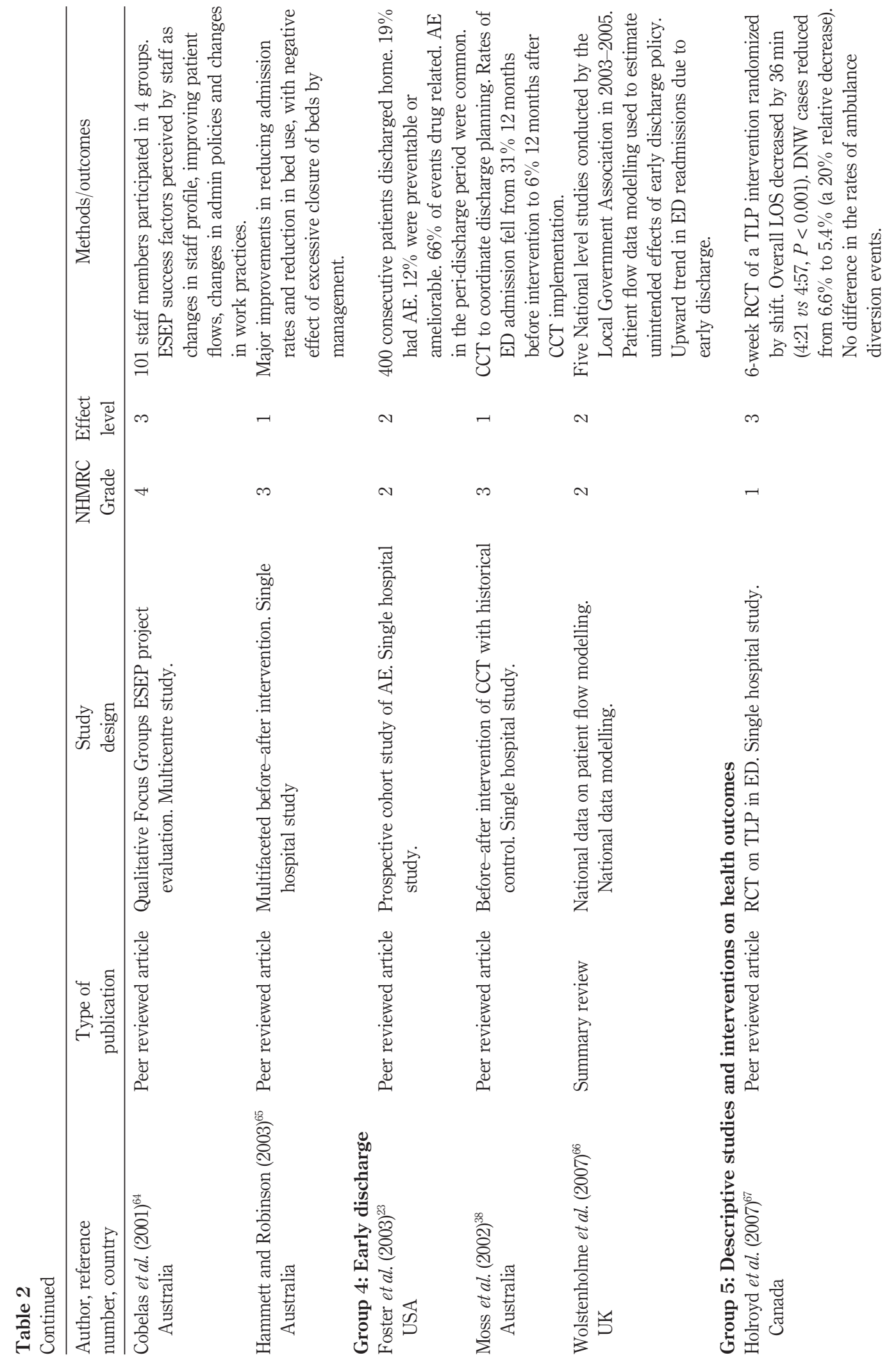




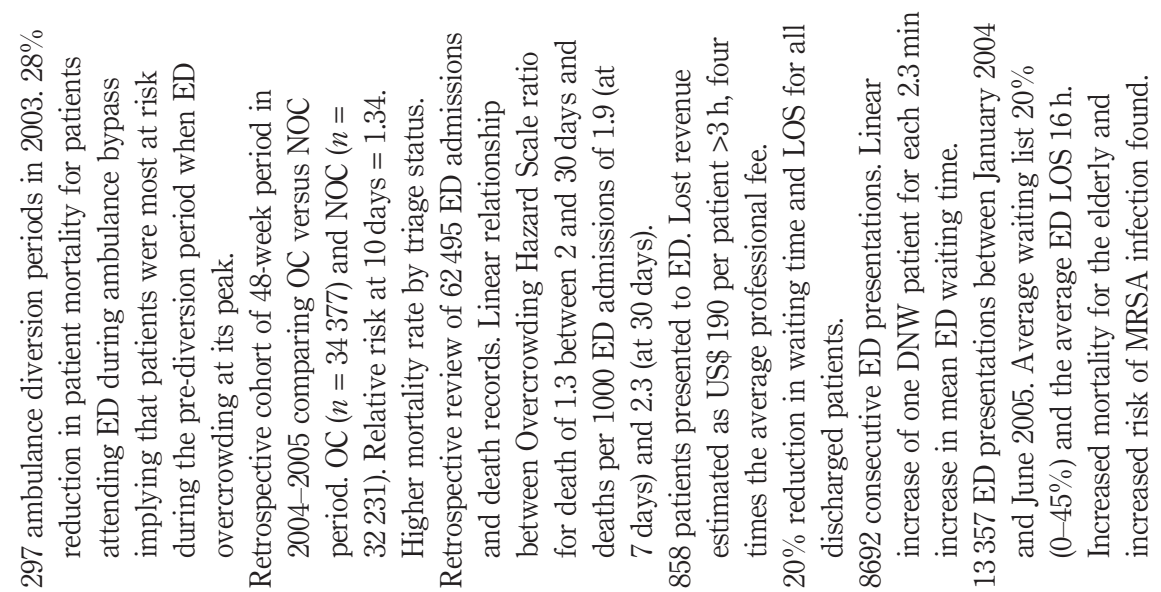

$\sim$

N

$\sim$

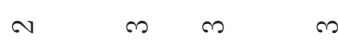
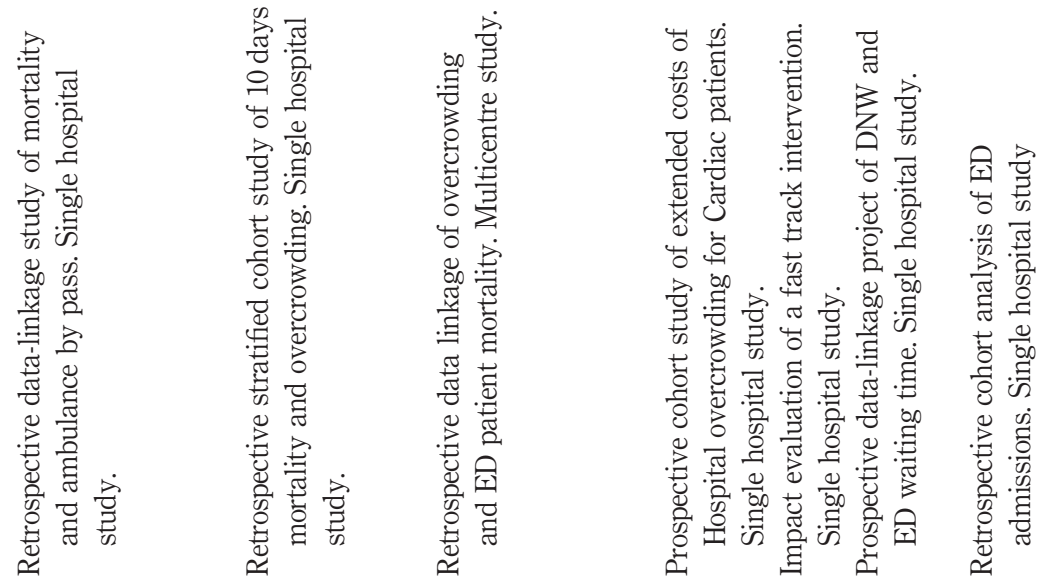

:

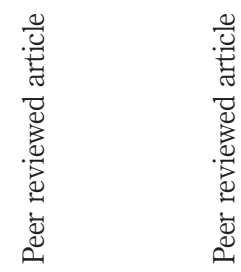

苞
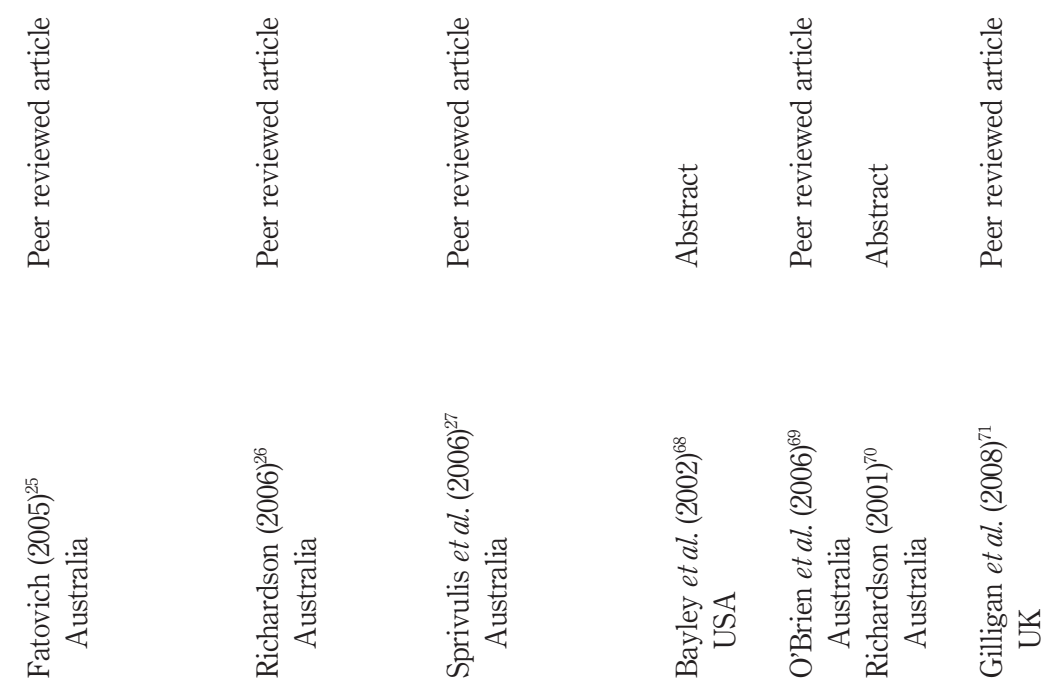
interventions according to five classification groups (see as follows), plus an additional category on descriptive interventions on health outcomes. The table shows brief details on each research paper including type of publication, study design, country of origin, method and outcomes, level of evidence and effect level.

\section{Grouping of initiatives (Table 2)}

Of the 51 intervention papers included in the analysis, $14 \%$ described initiatives to avoid admission (Group 1); $14 \%$ described interventions to provide alternatives to admission (Group 2); $51 \%$ focused on interventions to produce better management of existing resources (Group 3); 6\% on early discharge (Group 4); and 15\% included interventions on health outcomes (Group 5).

\section{Quality of research evidence (Table 2)}

The quality of research of the 51 intervention papers showed only $4 \%$ were randomized controlled trials (NHMRC Grade 1); 33\% were comparative studies (NHMRC Grade 2); 65\% were single hospital interventions (NHMRC Grade 3); and 2\% were qualitative studies or professional opinions (NHMRC Grade 4). Overall, $65 \%$ of the 51 intervention papers found a positive effect; $22 \%$ a negative effect; and $13 \%$ did not find a demonstrable effect.

Historical and prospective data show that when bed occupancy rates are reduced towards $85 \%$, this facilitates patient transfers to the wards, which in turn frees up space in the ED to see and process new patients. This then reduces ED length of stay, ${ }^{2,20,23,30}$ ambulance diversion rate ${ }^{21,25}$ and theatre cancellations. ${ }^{21}$

\section{Initiatives to avoid hospital admission (Table 2, Group 1)}

Successful initiatives to avoid hospital admission include transit lounges, observation wards, ${ }^{19,39}$ and multidisciplinary interventions ${ }^{13,29}$ including reducing overall hospital occupancy, ${ }^{30}$ additional ED staff ${ }^{31}$ and rescheduling of some services. However, ED expansion alone does not have a demonstrable effect on indicators of access block such as hospital diversion and length of stay. ${ }^{32}$ Some hospitals have reduced ED length of stay (another surrogate of access block) using strategies such as increasing working hours, and employing care coordinators, community nurses, ED nurses or additional medical officers at night. ${ }^{12,22,31,52-54,65,72-74,76}$

\section{Alternatives to hospital admission (Table 2, Group 2)}

Initiatives to avoid admission such as transit lounges ${ }^{13}$ and multifaceted interventions such as short stay wards ${ }^{62}$ and holding or transit bays ${ }^{74}$ have been combined with alternatives to admission such as fast track. ${ }^{34,40,69,75}$ ambulance diversion, ${ }^{50}$ risk screening tools ${ }^{54}$ and mental health triage ${ }^{59}$ Nurse-initiated X-ray radiograph improves patient satisfaction. ${ }^{74,77-78}$ Mental health patients benefit from the co-location of psychiatric emergency services within the ED. This improves clinical care for patients and the ED and reduces access block. $^{37,79-81}$

\section{Better management of existing resources (Table 2, Group 3)}

The majority of evidence compiled in our study relates to strategies to manage existing resources. Of these interventions, $62 \%$ were found to have a positive effect. $21,22,43,48,49,51-54,56,57,59,60,62,63,65,69,74,75$ A good example of these is the systems approach used by the Victorian Health Department. ${ }^{82-88}$ They used bed management processes to disseminate learning practices across the entire health system that included 11 metropolitan hospitals. Active bed management has also been used in the UK to improve service delivery. ${ }^{87-88}$

Another strategy to improve management of existing resources is a systematic hospital restructure such as that conducted in Canada in 20 hospitals between 1991 and 2000. The impact of incremental reductions in hospital resources was magnified as maximum operating capacity was approached. ${ }^{48}$

Bedside ED registration has been developed as a strategy for improving patient flow. This process consists of registering ED patients in the clinical care area to reduce registration delays and allow earlier clinical evaluation. This may reduce total ED time (a surrogate of access block), but was not sustainable at the end of one year as a single intervention. ${ }^{63}$

The ageing population is popularly believed to have placed an extra burden on ED hospitals. A recent study by Gray et al. ${ }^{89}$ demonstrated that although the Australian aged population increased by 18\% between 1993 and 2002 against a total population growth of $10 \%$, the proportion of hospital beds occupied by older patients remained stable at $47 \%$. The authors concluded that ageing of the Australian population by itself was not associated with an increase in the proportion of hospital beds used by older patients. 
Access to GP services within a hospital has shown mixed efficacy. It proved unsuccessful in some hospitals in Australia ${ }^{62}$ and New Zealand, ${ }^{90}$ yet was shown to be effective in the Netherlands. ${ }^{35,41}$ More research needs to be done to establish whether other as yet unrecognized factors have a counter-effect. An after-hours GP service located within an ED in South Australia was unsuccessful in reducing access block as a result of low numbers of patients being referred to the service. ${ }^{62}$

Han $e t a l^{32}$ demonstrated that individual initiatives such as expanding the ED capacity from 24 to 54 beds in isolation, without addressing other bottlenecks in the hospital are ineffective and insufficient to produce significant change in ambulance diversion rate or the proportion of patients who left without being seen (did not wait: DNW).

Policies to reduce or control overcrowding considered associated with $79 \%$ of access block patients in Canada, are perceived by ED directors to be largely ineffective. ${ }^{91}$ Thus in the UK, policies such as early hospital discharge have had unintended consequences, such as the creation of incomplete episodes of care resulting in increased readmissions ${ }^{66}$ In addition, telephone advice services fail to decrease the number of presentations to $\mathrm{ED}$, may lead to inappropriate presentations and or incorrect advice to stay at home. ${ }^{42}$

\section{Discussion}

Access block has been likened to an illness, with known morbidity and mortality rates. ${ }^{11}$ Indeed, if access block was considered an incurable disease, we would be forced to treat only some of the symptoms and the fundamental condition would remain unaffected. Table 2 demonstrates that some interventions are able to avoid admission of some patients, , $^{1929-33,39}$ or provide alternatives to admission, ${ }^{34-37,40-42}$ or improve management of existing resources, ${ }^{20-22,43-65}$ or have been successful in treating some key defined outcomes ${ }^{68-71}$ However, as long as the fundamental causes remain, the symptoms of access block sooner or later re-emerge.

A reduction in the number of hospital beds and increased occupancy rates above the recommended $85 \%$ in the name of operational efficiency has clearly had a negative effect, as the demand for hospital beds exceeds supply., ${ }^{2,92}$ Burns et $a .^{20}$ were successful in reducing admission rates but this improvement was jeopardized by excessive closure of medical beds, in response to the additional bed capacity need, causing hospital occupancy rate to exceed the optimum $85 \%$ level. Hammett and Robinson ${ }^{65}$ in Sydney demonstrated dramatic improvements as a result of multifaceted interventions in 2001, but occupancy rates in that hospital remained in excess of $90 \%$.

People most affected by access block and overcrowding are those who require unplanned admissions to hospital because of their medical condition., ${ }^{2,6-8,11}$ The reasons for some patient groups being more affected by access block are multifactorial and complex. Studies on access block and ED overcrowding that demonstrate an associated negative effect include deleterious effects on trauma patients with pneumonia, ${ }^{44}$ delays in transfer to ICU, ${ }^{45}$ delays in pain treatment, ${ }^{46,55}$ increased numbers of patients who did not wait for treatment, ${ }^{58,70} \mathrm{AE}^{23}$ and increased mortality. ${ }^{25-27,71}$

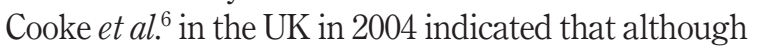
most evidence focuses on the magnitude and causes of delay in ED, there is little information on innovations and research in the areas of bed management, innovations to reduce delayed discharges, working practices and workforce numbers. We have found that there are no consistent outcome measures and definitions making it difficult to compare or combine study results, and assess their external validity. ${ }^{6}$

The majority of the evidence on interventions that work comes from single hospitals rather than multicentre interventions. More multilevel studies are needed to improve access block instead of retrospective or observational/descriptive studies. Thus for instance, the reduction of low acuity attendances to ED is not effective in reducing access block and should be discarded. 2,6,93-99

Studies described in Table 2 found some intervention effects to be partially successful or of short-term impact relating to clinical bed closures. As indicated in Figures 1 and 2, the rates of available beds at the national level have remained at the same level between 2.5 and 2.6 public acute beds per 1000 population since 2002, which ranks at the bottom of the Organisation for Economic Cooperation and Development (OECD) spectrum. This is compared with 1998 levels when the bed capacity was 3.2 beds per 1000 population, more in line with the OECD average of 4 beds per 1000 population. The level of bed capacity therefore needs to increase to match present and future demand. A major barrier to future initiatives is the absence of an integrated national bed strategy. The American College of Emergency Physicians have stated 'Only when all stakeholders agree that the problem is systemic and hospital-wide can solutions be implemented. ${ }^{94}$ 
We have found support for the Australian Medical Association recommendation of developing adequate number of beds to meet the needs of the population, in addition to adequate mental health and transitional care beds and the need for robust, long-term data collection and analysis systems. ${ }^{1}$

Finally, the complexity of the problem of access block and overcrowding is such that there are no single studies large enough to cover all the factors associated with the problem, nor are there ever likely to be. ${ }^{100}$ Funding complex interventions on a short-term basis is short-sighted, inefficient and expensive to run and maintain.

\section{ED research and funding}

We believe that the NHMRC and the Federal Government should provide long-term funding to support skilled persons emerging from short-term grants to assist in dealing with the problem. ED Research Grants should be developed with special emphasis on complex interventions to address access block and overcrowding. Therefore, infrastructure for ED research funding across hospitals needs to be developed. ED researchers need to create extensive networks, set up large multisite studies, and be able to conduct and coordinate longterm longitudinal, collaborative data-linkage studies at a national level with all key stakeholders. Many agree that there is a need for a national focus and strong leadership to deal with the problem of access block and overcrowding from all levels of government, academia and professional organizations.

\section{Conclusion}

There are limited numbers of multicentre interventional studies targeting access block. In addition, most interventions to date discussed in this report have been aimed at different surrogate markers of access block, but few studies have focussed on addressing access block directly. Carefully drafted systematic research projects must be developed in the future, led by ED researchers and aimed at a multilevel, multifaceted 'whole of hospital' approach to the problem of access block and ED overcrowding. ${ }^{101}$

\section{Competing interests}

Sally McCarthy is President of the ACEM.

\section{References}

1. Australian Medical Association (AMA). Position Statement on Quality and Safety in Public Hospitals. Kingston: AMA, 2006; Available from URL: http://www.ama.com.au/node/2540 [Accessed March 2010].

2. Australasian College for Emergency Medicine. Access block and overcrowding in emergency departments. 2004. Available from URL: http://www.acem.org.au/media/Access_Block1.pdf [Accessed February 2009].

3. King DL, Ben-Tovim DI, Bassham J. Redesigning emergency department patient flows: application of Lean Thinking to health care. Emerg. Med. Australas. 2006; 18: 391-7.

4. MJA Supplement. Health Services under siege: the case for clinical process redesign. Med. J. Aust. 2008; 188 (6 suppl.): s1-s40.

5. Australasian College for Emergency Medicine. Policy document - standard terminology. Emerg. Med. (Fremantle) 2002; 14: 33740.

6. Cooke M, Fisher J, Dale J et al. Reducing Attendances and Waits in Emergency Departments. A Systematic Review of Innovations. Report to the National Coordinating Centre for NHS Service Delivery and Organisation R\&D (NCCSDO). London: SDO, 2005. Available from URL: http://wrap.warwick.ac.uk/134/1/WRAP Szczepura_29-final-report.pdf [Accessed February 2009].

7. Anderson J, Bernath V, Davies J, Greene L, Ludolf S. Literature Review on Integrated Bed and Patient Management. Clayton, Victoria: Centre for Clinical Effectiveness Monash Institute of Public Health and Planning and Development Unit, Southern Health, Available from URL: http://www.health.vic.gov.au/ emergency/bgdocs/ibpmview.pdf [Accessed March 2010].

8. Dwyer J, Jackson T. Literature review: integrated bed and patient management. Commissioned by the patient management task force, Department of Human Services Victoria. 2001.

9. Stirling G, Higgins JE, Cooke MW. Violence in A\&E departments: a systematic review of the literature. Accid. Emerg. Nurs. 2001; 9: 77-85.

10. National Health and Medical Research Council. NHMRC additional levels of evidence and grades for recommendations for developers of guidelines. Stage 2 Consultation. Available from URL: http://www.nhmrc.gov.au/_files_nhmrc/file/guidelines/ final draft levels and grades dec 09.pdf [Accessed March 2010].

11. Braitberg G. Emergency department overcrowding: dying to get in? Med. J. Aust. 2007; 187: 624-5.

12. Cameron PA, Campbell DA. Responses to access block in Australia: Royal Melbourne Hospital. Med. J. Aust. 2003; 178: 109-10.

13. Fatovich DM. Responses to access block in Australia: Royal Perth Hospital. Med. J. Aust. 2003; 178: 108-9.

14. Cameron PA, Campbell DA. Access block: problems and progress. Med. J. Aust. 2003; 178: 99-100.

15. Department of Health and Ageing. The State of our Hospitals. 2004. Report available from URL: http://www. health.gov.au/internet/main/publishing.nsf/Content/ A5C070F4A914A406CA256F18004FCF33/\$File/sooph2004.pdf [Accessed February 2009].

16. Department of Health and Ageing. The State of our Hospitals. 2005. Report available from URL: http://www.health.gov.au/ 
internet/main/publishing.nsf/Content/ 00CF6462AB37F6B6CA257029001C1460/\$File/

sooph05report.pdf [Accessed February 2009].

17. Department of Health and Ageing. The state of our hospitals. 2008. Report available from URL: http://www.health.gov.au/ internet/main/publishing.nsf/Content/ E6CAF670D550F646CA25747700074A51/\$File/ SoOPH_2008_whole.pdf [Accessed February 2009].

18. Bagust A, Place M, Posnett JW. Dynamics of bed use in accommodating emergency admissions: stochastic simulation model. Br. Med. J. 1999; 319: 155-8.

19. Williams AG, Jelinek GA, Rogers IR, Wenban JA, Jacobs IG. The effect on hospital admission profiles of establishing an emergency department observation ward. Med. J. Aust. 2000; 173: $411-14$.

20. Burns CM, Bennett CJ, Myers CT, Ward M. The use of CuSum analysis in the early detection and management of hospital bed occupancy crises. Med. J. Aust. 2005; 183: 291-4.

21. Cameron P, Scown P, Campbell D. Managing access block. Aust. Health Rev. 2002; 25: 59-68.

22. Green LV, Soares J, Giglio JF, Green RA. Using queuing theory to increase the effectiveness of emergency department provider staffing. Acad. Emerg. Med. 2006; 13: 61-48.

23. Foster AJ, Murff HJ, Peterson JF, Gandhi TK, Bates DW. The incidence and severity of adverse events affecting patients after discharge from the hospital. Ann. Intern. Med. 2003; 138: 161-7.

24. Freeman J. The emerging subspecialty of hallway medicine. Can. J. Emerg. Med. 2003; 5: 283-5.

25. Fatovich DM. Effect of ambulance diversion on patient mortality: how access block can save your life. Med. J. Aust. 2005; 183: 672-3.

26. Richardson DB. Increase in patient mortality at 10 days associated with emergency department overcrowding. Med. J. Aust. 2006; 184: 213-16.

27. Sprivulis PC, Da Silva JA, Jacobs IG, Frazer AR, Jelinek GA. The association between hospital overcrowding and mortality among patients admitted via Western Australian emergency departments. Med. J. Aust. 2006; 184: 208-12.

28. Department of Infrastructure, Transport, Regional Development and Local Government. Road deaths Australia: 2007 statistical summary. 2008. Available from URL: http://www.bitre.gov.au/ publications/46/Files/mfreport.pdf [Accessed March 2010].

29. Caplan GA, Williams AJ, Daly B, Abraham K. A randomized, controlled trial of comprehensive geriatric assessment and multidisciplinary intervention after discharge of elderly from the emergency department - the DEED II study. J. Am. Geriatr. Soc. 2004; 52: 1417-23.

30. Dunn R. Reduced access block causes shorter emergency department waiting times: an historical control observational study. Emerg. Med. (Fremantle) 2003; 15: 232-8.

31. Donald KJ, Smith AN, Doherty S, Sundararajan V. Effect of an on-site emergency physician in a rural emergency department at night. Rural Remote Health 2005; 5: 380. Available from URL: http://www.rrh.org.au/publishedarticles/article_print_380.pdf [Accessed February 2009].

32. Han JH, Zhou C, France DJ, Zhong S et al. The effect of emergency department expansion on emergency department overcrowding. Acad. Emerg. Med. 2007; 14: 338-43.
33. Levin SR, Dittus R, Aronsky D et al. Optimizing cardiology capacity to reduce emergency department boarding: a systems engineering approach. Am. Heart J. 2008; 156: 1202-9.

34. Combs S, Chapman R, Bushby A. Evaluation of fast track. Accid. Emerg. Nurs. 2007; 15: 40-7.

35. Van Uden CJT, Winkens RAG, Wessling GJ et al. Use of out of hours services: a comparison between two organisations. Emerg. Med. J. 2003; 20: 184-7.

36. Sprivulis P, Carey M, Rouse I. Compliance with advice and appropriateness of emergency presentation following contact with the Health Direct telephone triage service. Emerg. Med. Australas. 2004; 16: 35-40.

37. Geller J, Janson P, McGovern E, Valdini A. Loneliness as a predictor of hospital emergency department use. J. Fam. Pract. 1999; 48: 801-4.

38. Moss JE, Flower CL, Houghton LM, Moss DL, Nielsen DA, McD Taylor D. A multidisciplinary care coordination team improves emergency department discharge planning practice. Med.J. Aust. 2002; 177: 427-31.

39. Mace SE, Graff L, Mikhail M, Ross M. A national survey of observation units in the United States. Am. J. Emerg. Med. 2003; 21: 529-33.

40. Simon HK, Ledbetter DA, Wright J. Societal savings by 'fast tracking' lower acuity patients in an urban pediatric emergency department. Am. J. Emerg. Med. 1997; 15: 551-4.

41. Van Uden CJT, Crebolder HFJM. Does setting up out of hours primary care cooperatives outside a hospital reduce demand for emergency care? Emerg. Med. J. 2004; 21: 722-3.

42. Graber DJ, Ardagh MW, O’Donovan P, St George I. A telephone advice line does not decrease the number of presentations to Christchurch Emergency Department, but does decrease the number of phone callers seeking advice. NZ Med.J. 2003; 116: U495. Available from URL: http://www.nzma.org.nz/journal/ 116-1177/495/ [Accessed February 2009].

43. Finn JC, Flicker L, Mackenzie E, Jacobs IG et al. Interface between residential aged care facilities and a teaching hospital emergency department in Western Australia. Med.J. Aust. 2006; 184: 432-5.

44. Carr BG, Kaye AJ, Wiebe DJ, Gracias VH et al. Emergency department length of stay: a major risk factor for pneumonia in intubated blunt trauma patients. J. Trauma 2007; 63: 9-12.

45. Chalfin DB, Trzeciak S, Likourezos A, Baumann BM et al. Impact of delayed transfer of critically ill patients from the emergency department to the intensive care unit. Crit. Care Med. 2007; 35: 1477-83.

46. Cordell WH, Keene KK, Giles BK, Jones JB et al. The high prevalence of pain in emergency medical care. Am. J. Emerg. Med. 2002; 20: $165-9$.

47. Diercks DB, Roe MT, Chen AY, Peacock WF et al. Prolonged emergency department stays of non-ST-segment-elevation myocardial infarction patients are associated with worse adherence to the American College of Cardiology/American Heart Association guidelines for management and increased adverse events. Ann. Emerg. Med. 2007; 50: 489-96.

48. Schull MJ, Szalai JP, Schwartz B, Redelmeier DA. Emergency department overcrowding following systematic hospital restructuring: trends at twenty hospitals over ten years. Acad. Emerg. Med. 2001; 8: 1037-43. 
49. Epstein SK, Tian L. Development of an emergency department work score to predict ambulance diversion. Acad. Emerg. Med. 2006; 13: 421-6.

50. Sprivulis P, Gerrard B. Internet-accessible emergency department workload information reduces ambulance diversion. Prehosp. Emerg. Care 2005; 9: 285-91.

51. Falvo T, Grove L, Stachura R et al. The opportunity loss of boarding admitted patients in the emergency department. Acad. Emerg. Med. 2007; 14: 332-7.

52. O'Connor AE, Lockney AL, Sloan PM, McGrail R. Does the presence of an emergency physician improve access based quality indicators in a rural emergency department? Emerg. Med. Australas. 2004; 16: 55-8.

53. Bucheli B, Martina B. Reduced length of stay in medical emergency department patients: a prospective controlled study on emergency physician staffing. Eur. J. Emerg. Med. 2004; 11: 29-34.

54. Hegney D, Buikstra E, Chamberlain C et al. Nursing discharge planning in the emergency departments: a Toowoomba, Australia, study. J. Clin. Nurs. 2006; 15: 1033-44.

55. Hwang U, Richardson LD, Sonuyi TO, Morrison RS. The effect of emergency department crowding on the management of pain in older adults with hip fracture. J. Am. Geriatr. Soc. 2006; 54: $270-5$.

56. Cardin S, Afilalo M, Lang E et al. Intervention to decrease emergency department crowding: does it have an effect on return visits and hospital readmissions? Ann. Emerg. Med. 2003; 41: 173-85.

57. Forero R, Mohsin M, McCarthy S et al. Prevalence of morphine use and time to initial analgesia in an Australian emergency department. Emerg. Med. Australas. 2008; 20: 136-43.

58. Mohsin M, Forero R, Ieaci S, Bauman AE, Young L, Santiano N. A population follow up study of patients who left an emergency department without being seen by a medical officer. Emerg. Med. J. 2007; 24: 175-9.

59. Smart D, Pollard C, Walpole B. Mental health triage in emergency medicine. Aust. N. Z. J. Psychiatry 1999; 33: 57-66.

60. Richardson JR, Braitberg G, Yeoh MJ. Multidisciplinary assessment at triage: a new way forward. Emerg. Med. Australas. 2004; 16: $41-6$.

61. Chia WT, Chen YS, Lin CF, Lin HHL. Difference in time to $\mathrm{X}$-ray with similar time to treatment decision leads to differences in waiting times of patients with hip fracture in a crowded emergency department. Emerg. Med. J. 2008; 25: $274-5$.

62. Ruffin RE, Hooper JK. Responses to access block in Australia: Queen Elizabeth Hospital Medical Division. Med. J. Aust. 2003; 178: $104-5$.

63. Takakuwa KM, Shofer FS, Abbuhl SB. Strategies for dealing with emergency department overcrowding: a one-year study on how bedside registration affects patient throughput times. $J$. Emerg. Med. 2007; 32: 337-42.

64. Cobelas C, Cooper C, Ell M, Hawthorne G, Kennedy M et al. Quality management and the emergency services enhancement program. J. Qual. Clin. Pract. 2001; 21: 80-5.

65. Hammett RJH, Robinson BG. Responses to access block in Australia: Royal North Shore Hospital. Med. J. Aust. 2003; 178: 105-7.
66. Wolstenholme E, Monk D, McKelvie D, Arnold S. Coping but not coping in health and social care: masking the reality of running organisations beyond safe design capacity. Syst. Dyn. Rev. 2007; 23: $371-89$.

67. Holroyd BR, Bullard MJ, Latoszek K et al. Impact of a triage liaison physician on emergency department overcrowding and throughput: a randomized controlled trial. Acad. Emerg. Med. 2007; 14: 702-8.

68. Bayley MD, Schwartz JS, Shofer FS et al. The financial burden of ED congestion and hospital overcrowding for chest pain patients awaiting admission. Ann. Emerg. Med. 2005; 45: 110-117.

69. O'Brien D, Williams A, Blondell K, Jelinek GA. Impact of streaming 'fast track' emergency department patients. Aust. Health Rev. 2006; 30: 525-32.

70. Richardson DB. Quantifying the effects of access block. [abstract]. Emerg. Med. (Fremantle) 2001; 13: A10.

71. Gilligan P, Winder S, Singh I, Gupta V, Kelly PO, Hegarty D. The boarders in the emergency department (bed) study. Emerg. Med. J. 2008; 25: 265-9.

72. Richardson DB. Responses to access block in Australia: Australian Capital Territory. Med. J. Aust. 2003; 178 (3): 1034.

73. Bernstein SL, Verghese V, Leung W, Lunney AT, Perez I. Development and validation of a new index to measure emergency department crowding. Acad. Emerg. Med. 2003; 10: 938-42.

74. Ashby RH. Responses to access block in Australia: Queensland. Med. J. Aust. 2003; 178: 107-8.

75. Hill NH. Responses to access block in Australia: the Alfred Hospital. Med.J. Aust. 2003; 178: 110-11.

76. Geelhoed GC, Geelhoed EA. Positive impact of increased number of emergency consultants. Arch. Dis. Child. 2008; 93: 62-4.

77. Tambimuttu J, Hawley R, Marshall A. Nurse-initiated x-ray of isolated limb fractures in the emergency department: research outcomes and future directions. Aust. Crit. Care 2002; 15: 119 22.

78. Cooper MA, Lindsay GM, Kinn S, Swann IJ. Evaluating emergency nurse practitioner services: a randomized controlled trial. J. Adv. Nurs. 2002; 40: 721-30.

79. Considine J, Martin R, Smit D, Winter C, Jenkins J. Emergency nurse practitioner care and emergency department patient flow: case-control study. Emerg. Med. Australas. 2006; 18: 385-90.

80. American College of Emergency Physicians. ACEP psychiatric and substance abuse survey. 2008. Available from URL: http:// www.acep.org/uploadedFiles/ACEP/Advocacy/federal_issues/ PsychiatricBoardingSummary.pdf [Accessed February 2009].

81. Fatovich DM, Girling S, Armstrong N. Access block of psychiatric patients in the Emergency Department. 24th Annual Scientific Meeting of the Australasian College for Emergency Medicine. Gold Coast, Australia, 27 November 2007.

82. Patient Management Task Force. Improving Hospital Care for Older Victorians. Paper No. 5. Melbourne: Victorian Government Department of Human Services, 2001. Available from URL: http://www.dhs.vic.gov.au/ahs/archive/patman/paper5.pdf [Accessed February 2009].

83. Patient Management Task Force. Metropolitan health and aged care services division. Department of Human Services Victoria Website. Available from URL: http://www.dhs.vic.gov.au/ahs/ archive/patman/0451200.pdf [Accessed March 2010]. 
84. Patient Management Task Force. A Ten-Point Plan for the Future. Melbourne: Victorian Government Department of Human Services, 2001. Available from URL: http://www.dhs.vic.gov.au/ ahs/archive/patman/paper8.pdf [Accessed March 2010].

85. Patient Management Task Force. Better Access for Patients: Extending Ambulatory Care and Same Day Services for Medical and Surgical Patients. Paper No. 3. Melbourne: Victorian Government Department of Human Services, 2001. Available from URL: http://www.dhs.vic.gov.au/ahs/archive/patman/paper3.pdf [Accessed March 2010].

86. Patient Management Task Force. Improving the Management of Multi-Day Admissions: Better Utilisation of Hospital Beds. Paper No. 4. Melbourne: Victorian Government Department of Human Services, 2001. Available from URL: http://www.dhs.vic.gov.au/ ahs/archive/patman/paper4.pdf [Accessed March 2010].

87. Proudlove NC, Boaden R. Using operational information and information systems to improve in-patient flow in hospitals. J. Health Organ. Manag. 2005; 19: 466-77.

88. Proudlove NC, Gordon K, Boaden R. Can good management solve the overcrowding in accident and emergency departments? Emerg. Med.J. 2003; 20: 149-55.

89. Gray LC, Yeo MA, Duckett SJ. Trend in the use of hospital beds by older people in Australia: 1993-2002. Med.J. Aust. 2004; 181: 478-81.

90. Wilson H. Co-locating primary care facilities within emergency departments: brilliant innovation or unwelcome intervention into clinical care? NZ Med. J. 2005; 118: 1221. Available from URL: http://www.nzma.org.nz/journal/118-1221/1633/content.pdf [Accessed March 2010].

91. Bond K, Ospina MB, Blitz S et al. Frequency, determinants and impact of overcrowding in emergency departments in Canada: a national survey. Health Care Qual. 2007; 10: 32-40.
92. King DL, Ben-Tovim DI, Bassham J. Redesigning emergency department patient flows: application of Lean Thinking to health care. Emerg. Med. Australas. 2006; 18: 391-7.

93. American College of Emergency Physicians. Emergency Department crowding: high-impact solutions. ACEP Task Force Report on Boarding. 2008. Available from URL: http://www3.acep.org/ assets/0/16/898/904/1678/4f7df6b1-68e7-45db-862e6b66c061676c.pdf [Accessed February 2009].

94. Canadian Association of Emergency Physicians and the National Emergency Nurses Affiliation. Joint statement of emergency department overcrowding. Can. J. Emerg. Med. 2001; 3: 82-4.

95. Schull MJ, Kiss A, Szalai JP. The effect of low-complexity patients on emergency department waiting times. Ann. Emerg. Med. 2007; 49: 257-64.

96. Sprivulis P. Estimation of the general practice workload of a metropolitan teaching hospital emergency department. Emerg. Med. (Fremantle) 2003; 15: 32-7.

97. Vertesi L. Does the Canadian emergency department triage and acuity scale identify non-urgent patients who can be triaged away from the emergency department? Can.J.Emerg. Med. 2004; 6: $337-42$.

98. Agouridakis P, Hatzakis K, Chatzimichali K et al. Workload and case-mix in a Greek emergency department. Eur. J. Emerg. Med. 2004; 11: 81-5.

99. Payne SMC. Identifying and managing inappropriate hospital utilisation: a policy synthesis. Health Serv. Res. 1987; 22: 709-67.

100. Fatovich DM. Recent developments: emergency medicine. $\mathrm{Br}$. Med.J. 2002; 324: 958-62.

101. Lowthian JA, Cameron PA. Emergency demand access block and patient safety: a call for national leadership. Emerg. Med. Australas. 2009; 21: 435-39. 